\title{
Current Immunosuppression in Abdominal Organ Transplantation
}

\author{
Raffaele Girlanda, Cal S. Matsumoto, \\ Keith J. Melancon and Thomas M. Fishbein \\ Transplant Institute, Georgetown University Hospital, Washington DC
}

USA

\section{Introduction}

Organ transplantation has saved the lives of thousands of patients beginning from the mid 1950s. At the end of 2007 the Organ Procurement and Transplantation Network (OPTN) database recorded 183,222 people living with a functioning graft in the United States (Wolfe et al., 2010). Over the last two decades survival rates have continued to improve and currently $81-91 \%$ of kidney transplant recipients and $74-79 \%$ of liver transplant recipients are alive 5 years post-transplant (Wolfe et al., 2010). This success is a dramatic improvement compared to the early era of transplantation and is the result of advances in organ preservation, surgical technique, intensive care and immunosuppression. Particularly, the development of potent immunosuppressive medications has contributed significantly to the success of organ transplantation by reducing the incidence of rejection and graft loss. In recent large studies the incidence of acute rejection is reported as low as $8-15 \% 1$ year after kidney transplant (Ekberg et al., 2009) and graft loss due to acute rejection has now become very uncommon.

Clinical immunosuppression after organ transplantation has come a long way over the last fifty years. It started with total body irradiation, steroids and azathioprine (see Starzl, 2000 for a review on the history of immunosuppression). The rationale behind total body irradiation was to control the immune response to the allograft by ablation of the bone marrow, a similar principle applied today with the use of depleting agents (see below). Other early attempts at controlling the bone marrow and obtain lymphocyte depletion included splenectomy, thymectomy and thoracic duct drainage, but these had limited success. Instead, anti-lymphocyte globulin (ALG), prepared from the serum of horses or rabbits inoculated with human lymphocytes, was introduced in 1966 with the aim of mitigating cellular immunity using heterologous antibodies. (Starzl et al., 1967)

From the early 1960 s to 1980 s post-transplant immunosuppression consisted of azathioprine, high dose corticosteroids and antilymphocyte globulin. Cyclosporine was introduced in the early 1980s, followed by monoclonal antibodies, then by tacrolimus in the 1990s and lately by mycophenolic acid and sirolimus (see list below). Immunosuppression regimens have changed since the early era of transplantation as a result of the development of new drugs. Furthermore, the number of available drugs continues to increase. This article will describe the immunosuppressive drugs currently used in clinical transplantation and will focus on recent developments. We will also review current organ-specific IMS protocols 
for kidney, liver, pancreas and intestine transplant to highlight the differences in abdominal organ transplantation that require specific immunosuppressive strategies (ie immunosuppression in the highly sensitized kidney recipient, prevention of disease recurrence after liver transplant, role of induction in intestinal transplantation). Finally, we will highlight current areas of ongoing research and future developments in clinical immunosuppression.

\section{Current immunosuppressive agents}

There are several immunosuppressive drugs currently used in different combinations in abdominal organ transplantation (see table 1). Most agents target $\mathrm{T}$ cell activation and proliferation, given the central role of $\mathrm{T}$ lymphocytes in organ rejection. Indeed, the control of T cell-based mechanisms is key to prevent rejection, especially in the early post-transplant period. However, increasing attention is being given to the role of $\mathrm{B}$ cells and to the production of alloantibodies in late graft injury and chronic rejection. In addition, components of the innate immune system (neutrophils, complement) are becoming the target for development of new immunosuppressive agents. Here we discuss the immunosuppressive agents currently used in clinical transplantation and present new drugs being investigated in clinical trials.

\begin{tabular}{|c|}
\hline Antibodies (monoclonal) \\
\hline Alemtuzumab \\
\hline Basiliximab \\
\hline Daclizumab \\
\hline Muromonab-CD3 (OKT3) \\
\hline Rituximab \\
\hline Antibodies (polyclonal) \\
\hline ALG \\
\hline Atgam \\
\hline Thymoglobulin \\
\hline Azathioprine \\
\hline Calcineurin inhibitors \\
\hline Cyclosporine \\
\hline Tacrolimus \\
\hline Corticosteroids \\
\hline mTOR inhibitors \\
\hline Everolimus \\
\hline Sirolimus \\
\hline Mycophenolic acid \\
\hline Mycophenolate mofetil \\
\hline Mycophenolate sodium \\
\hline Others \\
\hline Belatacept \\
\hline Bortezomib \\
\hline
\end{tabular}

Table 1. Immunosuppressive drugs currently used in clinical transplantation 


\subsection{Corticosteroids}

Corticosteroids (prednisone, prednisolone, methylprednisolone) were the first immunosuppressive drugs to be used in transplantation and remain today first line treatment across organs for both prevention and treatment of rejection. The multiple antiinflammatory and immunomodulatory effects on a wide variety of cells including lymphocytes, granulocytes, macrophages, monocytes and endothelial cells are well known and the molecular mechanisms of action of steroids have been described extensively (Adcock et al., 2000). Briefly, corticosteroids down regulate cytokine gene expression in lymphocytes, antagonize macrophage differentiation, inhibit neutrophil adhesion to endothelial cells thereby decreasing their extravasation to the site of inflammation, decrease circulating eosinophil and basophil counts, inhibit IgE-dependent release of histamine and leukotriene from basophils and inhibit degranulation of mast cells. Additionally, glucocorticoids downregulate endothelial cell function including expression of class II MHC antigen and expression of adhesion molecules.

Based on these multiple effects on different cellular components of the immune response corticosteroids are very effective in preventing and treating acute allograft rejection. Indeed episodes of acute rejection are routinely treated with pulse steroids with generally good response, although there are instances of steroid-resistant rejection episodes.

The multiple side effects of steroids are also well known and include impaired wound healing, increased risk of infection, hypertension, weight gain, hyperglycemia, osteoporosis, fluid retention, hirsutism, acne and cataracts . Side effects may have an important impact especially in the long term and in children (ie growth pattern), therefore multiple trials of steroid withdrawal and steroid-free regimens have been designed in an attempt to limit the side effects of corticosteroids, with variable results (see below specific organs). In addition, several steroid withdrawal protocols have been associated with increased acute rejection (Knight et al., 2010). Corticosteroids still maintain a central role in the armamentarium of immunosuppressive agents currently available in clinical transplantation.

\subsection{Azathioprine}

Azathioprine was the main immunosuppressive agent, with steroids, for many years in clinical transplantation. It is a nucleotide analogue originally developed during research on new chemotherapy agents for leukemia. The mechanism of action of azathioprine is to incorporate into and to halt DNA replication thus blocking the de-novo purine synthesis in lymphocytes. It was originally tested in experimental kidney transplantation in the 1960s (Calne et al., 1961) and it obtained improved graft survival with less toxicity compared to analogue agents such as 6-mercaptopurine. Azathioprine is now very rarely used and it has been replaced by mycophenolic acid (see below) in many transplant programs.

\subsection{Calcineurin inhibitors}

Calcineurin inhibitors (CNI) are main immunosuppressive agents in use today in virtually every transplant program. Cyclosporine and tacrolimus are the two CNI currently used in clinical transplantation. Their immunosuppressive effect is to block the production of proinflammatory cytokines including IL-2, INF- $\gamma$, TNF- $\alpha$ and to inhibit T cell activation and proliferation by inactivating calcineurin, an intracellular calcium/calmodulin phosphatase triggered by the engagement of $\mathrm{T}$ cell receptor by donor $\mathrm{MHC}$ and responsible for dephosphorilation of nuclear factor for activated $\mathrm{T}$ cells (NF-AT) which promotes the transcription of cytokine genes. 
Although CNI remain the cornerstone of current immunosuppressive protocols, increasing attention is being devoted to their long term side effects (ie nephrotoxicity). The impact of these side effects and the concomitant introduction of alternative immunosuppressive agents led to the design of trials to reduce CNI exposure. Strategies to limit CNI exposure include CNI minimization, avoidance, and withdrawal (Flechner SM et al., 2008) However, to date trials incorporating mycophenolate mofetil or mTOR inhibitors showed mixed results because of adverse events or lack of efficacy (Larson et al., 2006, Ekberg et al., 2007).

\subsubsection{Cyclosporine}

Cyclosporine, a metabolite extracted from the soil fungi Cylindrocarpon lucidum and Trichoderma polysporum, initially was investigated as an antifungal but was also shown to be immunosuppressive in mice models of skin allotransplantation. Its potent anti-lymphocyte properties prolonged the survival of kidney transplants in the dog. The introduction of cyclosporine in the early 1980s has revolutionized clinical transplantation and has remained the cornerstone of immunosuppression for kidney, liver, heart and other organs for many years. The mechanism of action and the immunologic effects of cyclosporine have been reported above. With cyclosporine a dramatic increase in early graft survival was observed in many centers with some programs reporting almost doubling their 1-year graft survival rate from $50 \%$ in the late 1970 s to $86 \%$ in the 1980 s (Merion RM et al, 1984). Since the early 1980s triple immunosuppressive therapy with cyclosporine, azathioprine and steroids has been standard protocol for a long time in many centers and has allowed dramatic growth of transplant programs worldwide.

The main side effects of cyclosporine are nephrotoxicity and hypertension. Other side effects include diabetes and cosmetic changes like gingival hyperplasia and hirsutism. With longterm follow-up, it has become apparent that up to $15 \%$ to $20 \%$ of patients treated with calcineurin inhibitors experience chronic renal insufficiency requiring dialysis and/or renal transplantation (Ojo et al., 2003). The nephrotoxicity of cyclosporine is thought to result from its vasoconstrictor effects on renal blood vessels. Although early toxicity resulting in renal dysfunction may be reversible, the late stages of cyclosporine nephrotoxicity resulting in advanced tubular interstitial fibrosis and scarring may be irreversible. Now cyclosporine is used less frequently since other potent immunosuppressive drugs became available (see below).

\subsubsection{Tacrolimus}

The introduction of tacrolimus has further improved the remarkable results previously obtained with cyclosporine by reducing rejection rates and improving long term graft function and survival (Busuttil et al., 2004).

Tacrolimus (FK506) is a metabolite of the fungus Streptomyces tsukubaensis. The mechanism of action of tacrolimus is identical to that of cyclosporine. Upon entering the cytoplasm, it binds to an immunophilin referred to as FK-binding protein 12 and inhibits calcineurin, preventing the dephosphorylation of the transcription factor NFAT and inhibiting the transcription of cytokines necessary for rejection. Tacrolimus has gradually replaced cyclosporine in many transplant programs since it was found to be much more potent then cyclosporine. Indeed, its first successful use was reported as rescue therapy for rejected liver grafts failing conventional therapy (Starzl et al., 1989). Subsequently, tacrolimus has gradually been included in routine immunosuppression protocols in liver transplantation. Multicenter trials compared the efficacy and safety of tacrolimus with cyclosporine and 
showed that tacrolimus was associated with significantly fewer episodes of corticosteroid resistant or refractory rejection, although graft survival and patient survival were not significantly different; additional findings included a lower incidence of chronic rejection and infection. (The U.S. Multicenter FK506 Liver Study Group, 1994; European FK506 Multicentre Liver Study Group, 1994)

Since the early 1990s, an increasing number of patients receiving liver, kidney, heart, and heart-lung has been successfully immunosuppressed with tacrolimus-based regimens rather than cyclosporine. In addition, tacrolimus has made a significant impact on the outcomes of intestinal transplantation (see below). As a result, currently many transplant programs worldwide have adopted tacrolimus-based immunosuppressive regimens. However, like for cyclosporine, the toxicity profile of tacrolimus has become evident with studies showing that the use of tacrolimus is associated with higher risk of diabetes post-transplant and with incidence of nephrotoxicity and neurotoxicity comparable or higher than those of cyclosporine (Ekberg et al., 2007).

Tacrolimus is administered twice daily. To improve compliance with the medication a modified-release once daily dose form of tacrolimus has been developed and shown to have equivalent systemic exposure of conventional twice-daily tacrolimus (Cross et al., 2007) and similar efficacy in preventing kidney (Kramer et al., 2010) and liver (Truneka et al., 2010) transplant rejection.

\subsection{Mycophenolic acid}

Mycophenolate mofetil and mycophenolate sodium are similar pro-drugs both converted to the active compound mycophenolic acid by liver metabolism and they will be discussed together. Mycophenolic acid emerged as a new immunosuppressive agent in the early 1990s with a mechanism of action different from CNI (Mele et al., 2000) (Stewart et al., 2001). Whereas cyclosporine and tacrolimus both inhibit the enzyme calcineurin and the induction of cytokine synthesis soon after $\mathrm{T}$ cell activation, mycophenolic acid has no direct effect on the production of cytokines but prevents $\mathrm{T}$ and $\mathrm{B}$ cell proliferation by inhibiting a pathway required for cell division. Mycophenolic acid is a selective and noncompetitive inhibitor of inosine monophosphate dehydrogenase, which is an important enzyme in the de novo pathway of guanine nucleotide synthesis. This results in the inhibition of DNA synthesis in $\mathrm{T}$ and B lymphocytes thereby inhibiting cell proliferation and function. Other cell types can use salvage pathways and are not affected, therefore the effects of mycophenolic acid are largely on the immune cells with few effects on the non-immune system. Clinically, mycophenolate acid has largely replaced azathioprine because of its fewer myelotoxic and hepatotoxic side effects. It is usually combined into a regimen including a calcineurin inhibitor and steroids.

Since the 1990s, when large, double-blind, randomized trials in kidney transplant recipients showed the efficacy of mycophenolate acid in preventing early acute rejection in combination with cyclosporine and prednisone, this drug has been used widely as a part of various combination regimens of immunosuppressive agents. Common mycophenolic acidrelated side effects comprise gastrointestinal symptoms such as abdominal pain, diarrhea and nausea, infections (cytomegalovirus) and myelosuppression, namely anemia and leucocytopenia, malignancy (post-transplant lymphoproliferative disorders and non melanoma skin cancer).

Mycophenolate sodium is an enteric-coated preparation that allows delayed release of the active drug in the small intestine rather than the stomach. This may help alleviate some of 
the gastrointestinal side effects of mycophenolate mofetil. There is no significant difference in rejection and side effects in large randomized trial of mycophenolate mofetil versus mycophenolate sodium (Ciancio et al., 2011). The ability of mycophenolic acid to facilitate sparing of other immunosuppressive agents, particularly cyclosporine and its related nephrotoxicity, is promising. By permitting reduction in cyclosporine doses, mycophenolic acid may stabilize or improve renal graft function in patients with cyclosporine-related nephrotoxicity or chronic allograft nephropathy.

\section{5 mTOR inhibitors}

The mTOR inhibitors sirolimus and everolimus are among the most recently introduced immunosuppressive agents with a mechanism of action different from CNI and from antimetabolites. Sirolimus (or rapamycin) is a macrolide antibiotic, structurally similar to tacrolimus, isolated from the fungus Streptomyces hygroscopicus in 1968 and found to have immunosuppressive properties in the late 1980s. Like the calcineurin inhibitors, sirolimus acts by binding to an intracellular immunophilin FKB12. This complex sirolimusimmunophilin inhibits a protein called mammalian target of rapamycin (mTOR). Inhibition of mTOR results in selective inhibition of synthesis of new ribosomal proteins which are essential for progression of the cells from the G1 to the $S$ phase. This results in blockage of $T$ cell activation. In addition, sirolimus has been associated with inhibition of fibroblast growth factors required for tissue repair. This antifibrotic effect has two potentially beneficial effects after transplantation in reducing the progression to fibrosis in post liver transplant hepatitis C recurrence (see below) and in reducing the risk of malignancy in transplant recipients because of its antiangiogenic effects (Geisler et al., 2010).

The half life of sirolimus is 60 hours which allows single daily dose unlike other agents given twice daily and this has an important impact on patient compliance to immunosuppression regimens. Everolimus is a modified form of sirolimus to improve its absoprion. Its half life is shorter and is administred twice daily. Everolimus is currently undergoing clinical trials in liver transplantation. In addition to being used as immunosuppressant, it has been investigated in the treatment of renal cell carcinoma for its proliferation signal inhibition and in drug-coated stents to prevent restenosis of coronary arteries for its antifibrotic effect (Gabardi et al., 2010)

There have been a number of studies investigating the impact of adding sirolimus to low dose CNI regimens in order to reduce nephrotoxicity of CNI after kidney (Schena et al., 2009), liver (Harper et al., 2011) and heart (Raichlin et al., 2007) transplantation. The use of sirolimus with mycophenolate mofetil or azathioprine to avoid de novo CNI exposure has improved glomerular filtration rate for at least two years in most studies in kidney transplantation with comparable incidence of rejection, however experience is limited in liver and heart transplantation. However, there have been also reports of an increased risk of nephrotoxicity when combining sirolimus with high doses calcineurin inhibitors (Kahan, 2000)

Sirolimus, unlike calcineurin inhibitors, has been shown to enhance the development and function of regulatory $\mathrm{T}$ cells, a subset of $\mathrm{CD} 4(+) \mathrm{CD} 25(+)$ lymphocytes with the ability to suppress alloimmune responses in vitro and in vivo. It is therefore being evaluated as a component of strategies to promote tolerance in organ transplant recipients (Knektle 2010). In intestinal transplant recipients the introduction of sirolimus in tacrolimus-based regimens has significantly delayed the onset and reduced the severity of rejection (see below).

The adverse effects of sirolimus include thrombocytopenia, leukopenia, anemia, arthralgias, hyperlipidemia, pneumonitis, and diarrhea. There have also been reports of wound 
complications (delayed wound healing, incisional hernia) in the post-transplant period, an affect probably secondary to its antiproliferative effects on fibroblasts. Oral ulcers were seen with the liquid preparation; however, this seems to be less frequent with the use of the pill preparation.

\subsection{Antibodies}

The use of antibodies as part of the immunosuppression regimen post-transplant dates from the beginning of clinical transplantation when anti-lymphocyte globulin (ALG) prepared from the serum of horses or rabbits inoculated with human lymphocytes was added to azathioprine and steroids. In 1986 muromonab CD3, a monoclonal antibody (mAb) targeting CD3, was first approved for prevention and treatment of renal allograft rejection. Originally, the rationale for the use of antibodies as immunosuppressants was to deplete and block the function of immune competent cells. The purified IgG fraction of polyclonal antibody preparations is directed against cell-surface molecules expressed on T cells, B cells, NK cells and macrophages, causing complement mediated cell lysis, uptake of opsonised cells by the reticulo-endothelial system and modulation of surface receptors of lymphocytes. Infact the administration of polyclonal antibodies results in profound lymphopenia. Polyclonal antibodies are obtained by inoculating rabbits or horses with human lymphocytes or thymocytes. Currently available preparations include Thymoglobulin and Atgam. Monoclonal antibodies are produced in response to a single antigen. These include the mouse monoclonal antibody muromonab (OKT3), which is specific to the CD3 receptor and was the first monoclonal antibody to be used in transplantation to treat acute rejection. Other monoclonal antibodies include the anti-IL-2 receptor antibodies daclizumab and basiliximab, anti CD20 rituximab, antiCD52 alemtuzumab. Other new mAbs are emerging, targeting co-stimulatory signals, cell surface receptors and novel protein constructs.

Antibodies are further classified into lymphocyte-depleting or nondepleting agents (review Klipa et al., 2010) The total lymphocyte counts and CD3 counts are usually measured during therapy to monitor the achievement of effective depletion and to make dose adjustments in case of incomplete depletion.

Currently, antibodies are administered as induction immunosuppression to the majority of kidney, pancreas and intestine transplant recipients in the United States, and less frequently to liver recipients. Induction therapy, as opposed to maintenance immunosuppression, refers to the use of biological agents and high dose steroids to prevent immune engagement and T-cell activation during tissue injury from organ preservation, reperfusion, and alloresponse immediately after transplant. The agents most commonly used are thymoglobulin and alemtuzumab (depleting) and basiliximab, daclizumab and rituximab (non depleting) (review in Aparna et al., 2009).

The benefits of induction therapy include a decreased incidence and delayed onset of acute rejection, and also delayed introduction of or lowering dose of CNI in the early posttransplant period allowing for peri-operative renal dysfunction to recover. Other uses of antibodies are in desensitization protocols in sensitized kidney transplant recipients (see below) and in the treatment of steroid resistant rejection. Rituximab has also been used to treat antibody-mediated rejection in kidney transplant (Kaposztas et al., 2009). In addition to considerable cost, side effects include cytokine release phenomena secondary to cytolysis and characterized by fevers, chills, hypotension. Other side effects are nausea, diarrhea, arthralgias, thrombocytopenia, dyspnea, and seizures. The risk of infection and of posttransplantation lymphoproliferative disease is increased with antibody therapy. 


\subsection{New immunosuppressive drugs}

Different pathways and stages of the immunologic response are the target of strategies to develop new immunosuppressive drugs: cell-surface molecules, signaling mechanisms, Tcell proliferation, cell trafficking and cell recruitment.

New immunosuppressive drugs include mainly proteins targeting T-cell and B-cell surface receptors and non-protein drugs (also called small molecules) targeting intracellular pathways. Belatacept is a fusion protein composed of the Fc fragment of a human IgG1 immunoglobulin linked to the extracellular domain of CTLA-4. (review Weclawiak et al., 2010) It represents a new class of immunosuppressants. Unlike calcineurin inhibitors that block or diminish the effects of T-cell activation on allografts, belatacept prevents T-cell activation by selectively blocking T-cell costimulation molecules. In the initial trial in kidney transplant recipients it was as effective as cyclosporine in preventing acute rejection but with better preservation of kidney function and reduction of chronic allograft nephropathy (Vincenti et al., 2005) The stability of graft function and the safety profile of belatacept at 5 years has been reported in a subsequent study (Vincenti et al., 2010).

Memory $\mathrm{T}$ cells play a crucial role in acute and chronic rejection and are a potent barrier to transplantation tolerance. Alefacept, a fusion protein combining Leukocyte Function associated Antigen-3 (LFA3) with IgG currently approved for psoriasis, binds to CD2 on T cells (Ellis et al, 2001). Unlike belatacept that prevents activation of naïve $\mathrm{T}$ cells, alefacept targets memory $\mathrm{T}$ cells (Weaver et al., 2008) since CD2 is espressed more on memory than naïve T cells.

Efalizumab (Dedrick et al., 2002) is a humanized antiCD11a (LFA1) monoclonal antibody used in patients with chronic plaque psoriasis (Kuschei et al., 2011). It blocks the binding of LFA1 to intracellular adhesion molecule-1 (ICAM-1) causing loss of activation, adhesion and migration of T-cells. Preliminary experience with efalizumab in kidney transplantation showed efficacy in controlling rejection but raised concern of overimmunosuppression since $8 \%$ of patients developed post-transplant lymphoproliferative disease (Vincenti et al., 2007). New non-protein drugs (also identified as small molecules) target intracellular pathways of the immune response to the allograft, such as Janus kinase proteins (JAK), which mediate signal transmission between cell membrane receptors and the nucleus. The immunosuppressive effect of inhibition of JAK3 results from blocking the signaling of the gamma chain subfamily of cytokines (interleukins 2, 4, 7, 9, 15 and 21). Tofacitinib, a Janus kinase 1/3 inhibitor developed for the treatment of rheumatoid arthritis (Flanagan et al., 2010) prolonged kidney allograft survival in cynomolgus monkeys without concomitant use of calcineurin inhibitor (Borie et al., 2005). In clinical kidney transplantation it has been used in a calcineurin inhibitor- free regimen (Busque et al., 2009). This study reported comparable acute rejection rates between tofacitinib and tacrolimus-based immunosuppression but raised concern of overimmunosuppression in the form of increased BK virus infection rates. Two new other biologic agents being developed are 4D11, a costimulation blockade agent targeting CD40 (Aoyagi et al., 2009) and natalizumab, a humanized IgG4 approved for multiple sclerosis and Crohn's disease targeting alpha4 submunit of integrins thus inhibiting leucocyte adhesion (Hutchinson 2010).

Voclosporine (ISA247) is a novel oral semisynthetic structural analogue of cyclosporine that has been modified at the first amino acid residue of the molecule. This drug has been shown to be more potent than cyclosporine in vitro and in vivo in rat heterotopic heart transplantation. The advantage of this cyclosporine-analogue drug is the lack of nephrotoxicity. There is still limited experience with this drug in clinical transplantation. 
Preliminary results show non-inferiority to tacrolimus in preventing rejection (Gaber et al., 2008). More data is needed on the efficacy and safety profile in the long term.

Protein kinases (PKC) play a key role in signaling pathways downstream of the T-cell receptor (signal 1) and CD28 (signal 2) and thereby are involved in early T-cell activation. There are several isoforms of PKC. PKCh is largely restricted toT lymphocytes and mediates activation of the transcription factors activator protein- 1 and nuclear factor (NF) jB, leading to downstream IL-2 production. The PKCh knockout mice demonstrate impaired T-cell activation. Sotrastaurin (AEB071) is a new oral low molecular weight compound that effectively blocks early T-cell activation by selective inhibition of PKC and therefore has a different mechanism of action from that of the CNIs. (Kovarik et al., 2011)

In kidney transplantation the deleterious effects of the humoral (antibody-mediated) component of acute rejection and their impact on long term graft survival are being increasingly recognized. This has prompted the development of more targeted antihumoral therapies. Bortezomib is an antineoplastic agent originally developed for the treatment of multiple myeloma. It is a proteasome inhibitor that induces apoptosis in rapidly dividing cells with active protein synthesis like plasma cells. In kidney transplantation it has been reported to revert antibody-mediated rejection (Perry et al., 2009, Walsh et al., 2010). Early antibody-mediated rejection demonstrated increased response to proteasome inhibitors than late AMR (Walsh et al.,2011)

\section{Immunosuppression in kidney transplantation}

Kidney transplant is the most frequently performed among abdominal organ transplants and in 2010 16,896 patients received a kidney transplant in the United States, 37\% of which were from live donor. (unos) (http://optn.transplant.hrsa.gov/latestData/rptData.asp). The advantages of live-donor versus deceased donor kidney transplant are multiple including shorter time on the waiting list, shorter cold ischemia time (ie the interval between organ procurement and transplantantation), less preservation injury and overall better graft function in the short and long term. However, the immunologic risk in live-donor kidney transplant is not inferior to deceased donor, even in case of live-related donor (ie between non-identical siblings). On the contrary, live donor kidney transplant is becoming a bigger immunological challenge than deceased donor with the increasing number of transplants performed in highly sensitized or ABO incompatible recipients (see below).

There are several immunosuppression protocols currently used in kidney transplantation, but the majority include induction with depleting or non-depleting antibodies and maintenance immunosuppression based on a combination of agents (usually triple therapy) including $\mathrm{CNI}$, mycophenolic acid, sirolimus and steroids.

Current acute rejection rate is $10-15 \%$ (Gaston et al., 2009) and usually the function of the graft is maintained after treatment of the rejection episode. Immunosuppression regimens currently available are very effective in treating episodes of acute rejection so that graft loss due to acute rejection has now become a rare event. Instead, chronic rejection (or chronic allograft nephropathy) remains a major cause of graft loss, usually a late event (years) after transplant. The causes of chronic allograft nephropathy and graft loss are multiple including repeated episodes of rejection, disease recurrence, CNI toxicity and others. Indeed, one of the main side effects of CNI is nephrotoxicity, affecting up to $16 \%$ of non-renal transplant recipients at 3 years and resulting in end stage kidney disease requiring dialysis in $5-20 \%$ of patients 5 years after transplant (Ojo et al.,2003). This prompted the design of several trials 
of CNI withdrawal, minimization or avoidance in an attempt to limit the impact of CNI nephrotoxicity. However, CNI cannot be avoided completely in kidney transplantation without paying the price of high rejection rate up to $53 \%$ within the first year (Vincenti et al., 2001). So another approach would be to reduce CNI (Ekberg et al., 2007).

Increasing attention is being recently devoted to the role of late antibody mediated rejection causing chronic sub-acute immune mediated injury. Chronic antibody mediated injury is being recognized as a cause of late graft loss and is a process that is not controlled by CNI or other current drugs (Colvin 2010, Kirk et al., 2010).

\section{Highly sensitized and $\mathrm{ABO}$-incompatible recipients}

Immunologic sensitization in a transplant candidate refers to the presence of pre-formed antibodies and it is measured as PRA (Panel of Reactive Antibodies), which express the percentage of the antigenic repertoire in the general population to which the transplant candidate has developed antibodies (0-100\%). The causes of sensitization are multiple and include blood transfusions, previous transplant, pregnancies and infections. Highly sensitized patients have PRA of $80 \%$ or higher. These patients are at greater risk of rejection and graft loss than non-sensitized patients. In addition, highly sensitized patients are likely to wait longer for a 0 -mismatch kidney graft than non-sensitized patients. This has prompted the development of desensitization protocols to enable highly sensitized patients to receive a successful transplant in a timely manner. The aim of desensitization protocols is to reduce the amount of circulating HLA antibodies and to prevent the formation of new antibodies. Strategies currently adopted to achieve these goals include plasmapheresis to remove HLA antibodies, intravenous immunoglobulins (IvIg) to neutralize circulating antibodies and to inhibit complement activation, rituximab (a chimeric anti CD20 monoclonal antibody) to deplet $\mathrm{B}$ cells and, more recently, bortezomib, a proteasome inhibitor that targets plasma cells (see above). The protocol at our Institute also includes mycophenolate sodium started the week before transplant as part of the strategy to control the B cell component of the immune response (Melancon et al., 2011) Current results of desensitization programs demonstrate graft function and graft survival comparable to nonsensitized patients (Montgomery et al., 2010, Melancon et al., 2011, Niederhaus et al., 2011). Until recently, another barrier to a successful kidney transplant has been ABOincompatibility between donor and recipient (ie donor blood type is A or B and recipient blood type is O). Over the last decade this barrier has been overcome in some transplant centers by the implementation of programs of paired kidney exchange and antibody reduction therapies in which a number of donor-recipient pairs are entered into a pool and matched according to blood type compatibility (Montgomery et al., 2006) (Melancon et al., 2011). In addition to entering an exchange program, the recipient of an ABO incompatible pair with high isohemoagglutinin titers can also be treated with plasmapheresis and anti-B cell agents to reduce the isohemoagglutinin titer to 1:16 or below, a level considered safe to proceed with $\mathrm{ABO}$ incompatible transplant. Since the number of kidneys from deceased donors remains inadequate, living kidney donation has allowed for more patients to be removed from the waiting list. Programs of paired kidney exchange and the implementation of antibody reduction therapies have allowed the use of $\mathrm{ABO}$ incompatible donors and also the inclusion of non-directed good Samaritan donors, who enter the system with a desire to donate a kidney to someone for purely altruistic purposes. These strategies have all contributed to magnify the opportunities for a successful transplant for patients who otherwise would have had to wait 5-7 years for a matched kidney from deceased donor. In 
our recent series, all patients received a transplant within 90 days of their initial evaluation for living donor transplantation (Melancon et al., 2011).

\section{Immunosuppression in liver transplantation}

Liver transplantation has become an established treatment for patients with decompensated cirrhosis and acute liver failure and today the liver is the second most commonly performed abdominal organ transplant. Currently, 6,000 liver transplants are performed in the US yearly (unos). (http://optn.transplant.hrsa.gov/ar2009/Chapter_IV_AR_CD.htm?cp=5\#TOC).

In parallel to the success of kidney transplantation, the outcomes of liver transplantation have continued to improve over the last two decades following better surgical techniques and the introduction of more potent immunosuppression. The introduction of cyclosporine first and later tacrolimus has allowed to control the rejection rate and prolong allograft survival ((Starzl et al., 1985, Busuttil et al., 2004). Especially tacrolimus has played an important role in liver transplantation since its introduction by allowing to rescue grafts from cyclosporine resistant rejection (Starzl et al., 1989). As a result, cyclosporine is less commonly used today in liver transplantation and most immunosuppression protocols are based on tacrolimus, associated to mycophenolic acid and steroids (reviewed in Geissler et al., 2009 and Pillai et al., 2009).

Usually liver transplant recipients do not receive antibody-based induction immunosuppression. Rather, high-dose methylprednisolone (500 $\mathrm{mg}-1 \mathrm{~g}$ ) is given intravenously as induction at the time of implantation of the liver and rapidly tapered from the time of surgery to a daily maintenance dose of 5 to $10 \mathrm{mg}$ per day. Many programs taper and discontinue prednisone at 3 to 6 months to avoid the side effects of long-term prednisone use. Prednisone cessation does not seem to have a negative impact on graft function. Indeed, steroid withdrawal trials have demonstrated that corticosteroid-free regimens do not lead to increased rejection rates. However, in patients transplanted for immune-mediated liver disease such as primary biliary cirrhosis, primary sclerosing cholangitis and autoimmune hepatitis it seems prudent to maintain prednisone therapy in the long term, albeit at a low-dose, in order to reduce the risk of disease recurrence.

Corticosteroids are also used in the treatment of episodes of acute cellular rejection: intravenous methylprednisolone is usually given at a dose of 1,000 $\mathrm{mg}$ on alternate days for a total of 3 doses, followed by taper.

Acute rejection does not impact on graft function in the long term in the vast majority of cases given the resilience and the regenerative capacity of the liver as opposed to kidney or other solid organs.

An important issue in immunosuppression in liver transplant recipients is the prevention of nephrotoxicity associated with CNI. Chronic renal damage is affecting up to $16 \%$ of nonrenal transplant recipients treated with CNI (Ojo et al., 2003) and the search for the best renal sparing immunosuppression strategy in liver transplantation is still ongoing. A key factor seems to be the tailoring of the immunosuppression regimen to the individual patient. In patients with renal insufficiency at the time of transplant one strategy is to hold calcineurin inhibitors and to use an IL-2 receptor blocker as induction agent. This will obtain effective immunosuppression early post-transplant allowing the introduction of CNI to be delayed until after resolution of peri-operative renal dysfunction. In the event of nonrecovery of renal function, the addition of sirolimus may be considered. A number of studies have reported on the use of sirolimus in patients with renal insufficiency after liver 
transplantation and especially in those with calcineurin inhibitor (CNI)-associated nephrotoxicity. The results of these studies have not been conclusive. A recent meta-analysis showed that conversion to sirolimus from CNIs in LT recipients with renal insufficiency [glomerular filtration rate (GFR) $<60 \mathrm{~mL} /$ minute or creatinine level $\geq 1.5 \mathrm{mg} / \mathrm{dL}$ ] is associated with a non-significant improvement in renal function. In addition, although patient and graft survival were not significantly different, infections, ulcers and discontinuation of therapy were significantly more common in patients treated with sirolimus compared to control (Asrani et al., 2010). This adds to an earlier concern raised by previous randomized studies when sirolimus was first tried in liver transplantation in 1999. One study (Wiesner et al 2002) reported increased risk of hepatic artery thrombosis and death compared to standard immunosuppression. This study was interrupted and led the FDA to issue an alert on the use of sirolimus in liver transplant. (http:/ / www.fda.gov/Drugs/DrugSafety/PostmarketDrugSafetyInformationforPatientsan dProviders/DrugSafetyInformationforHeathcareProfessionals/ucm165015.htm).

However, sirolimus is currently being used by transplant programs in selected patients. A recent single center retrospective study on 148 patients converted to sirolimus at any time post-transplant for renal function impairment or for progression of fibrosis in HCV positive recipients documents that sirolimus was safe and effective with low rejection rates $(3.4 \%)$ and no cases of hepatic artery thrombosis (Harper et al., 2011). Another large single center retrospective study reported on the safety and efficacy of sirolimus in liver transplant with lower incidence of rejection and similar survival rates compared to other regimens (Campsen et al., 2011).

Finally, other recent studies have reported that the antifibrotic and antiangiogenic effects of sirolimus may have a favorable impact in $\mathrm{HCV}$ positive recipients and patients transplanted for hepatocellular carcinoma, respectively (see below).

A special consideration has been given over the last few years to immunosuppression regimens used in $\mathrm{HCV}$ positive liver transplant recipients. HCV-related cirrhosis is now the most common indication for liver transplantation in the US and HCV recurrence in the graft is a major risk factor for graft loss. To date there is no single best strategy to successfully prevent $\mathrm{HCV}$ recurrence post-transplant, although new antivirals are being developed that may have a positive impact. The management of immunosuppression in HCV liver transplant recipients has been the focus of several studies but consensus on the best immunosuppression regimen in $\mathrm{HCV}$ recipients is lacking. However, it seems to be now accepted in many centers that the use of steroids, especially high-dose intravenous boluses to treat acute cellular rejection should be considered very carefully in patients with hepatitis C because of the risk of severe recurrence of hepatitis C. (Berenguer 2011). Therefore, the prevention of rejection by obtaining and maintaining adequate levels of tacrolimus from the very early post-operative period is very important. Cyclosporine has been suggested to be superior to tacrolimus in controlling HCV recurrence post-transplant given the antiviral effects of cyclosporine in vitro but clinical trials failed to confirm this expectation and currently there is no evidence that the choice of CNI (cyclosporine or tacrolimus) makes a significant difference in outcome in HCV recipients (Berenguer et al., 2010). Antiviral therapy with interferon and ribavirin is an option in selected transplant recipients with recurrent $\mathrm{HCV}$ : progression to cirrhosis is slower, risk of graft decompensation is lower and patient survival is longer in responders to antiviral treatment compared to non-responders (Berenguer et al., 2008). However, the pro-inflammatory effects of interferon increase the risk of acute rejection, chronic rejection and de-novo autoimmune hepatitis post-transplant 
(Nazia et al., 2011). Pre-transplant antiviral treatment is poorly tolerated in Child C patients (Melero et al., 2009).

The antifibrotic effect of sirolimus has been considered to have a potential impact on slowing down fibrosis progression in HCV-positive recipients (Wagner et al., 2010). A recent study on 88 patients treated with sirolimus-based immunosuppression reports that, although timing or severity of post-transplant HCV recurrence were not affected, hepatitis activity and fibrosis scores were lower on serial biopsy compared to conventional immunosuppression regimens (Asthana et al., 2011). Further studies will have to confirm the role of sirolimus in $\mathrm{HCV}$-infected grafts.

Liver transplantation is the most radical and successful treatment for selected patients with hepatocellular carcinoma (HCC) who fulfill transplant criteria. Tumor recurrence affects 10$20 \%$ of patients within 2 years after transplant and is a major determinant of patient survival. Multiple factors determine the risk of recurrence of HCC after liver transplant, including staging and biologic aggressivity of HCC. Post-transplant immunosuppression increases the risk of tumor recurrence and the choice of the immunosuppression regimen may have an impact on outcomes. Drugs like mTOR inhibitors (sirolimus, see above) effectively reduce cell growth and angiogenesis in animal models of hepatocellular cancer (review in Treiber 2009) and may have a role in reducing the risk of recurrence in patients transplanted for HCC. In a recent study patients transplanted for HCC and treated with sirolimus had lower recurrence rates than patients treated with tacrolimus (Chinnakotla et al., 2009); a subsequent study on registry data confirmed better survival rates in sirolimus patients compared to non-sirolimus (Toso et al., 2010).

New drugs are being developed for the treatment of HCC. Sorafenib is a tyrosine kinase inhibitor shown to increase survival in patients with advanced HCC (Llovet et al., 2008). Trials are ongoing on the use of sorafenib to prevent recurrence after transplant (Villanueva et al., 2011).

Currently, antibodies are not commonly used in liver transplantation. OKT3 has been in the past the most commonly used monoclonal antibody in liver transplantation. It was originally introduced in 1987 for prophylaxis of acute cellular rejection but now it is mainly used in patients with steroid-resistant cellular rejection. The use of OKT3 and of other depleting agents is associated with early and severe recurrences of hepatitis $C$ and must be used with caution in this cohort of patients. (Rosen et al., 1997, Eghtesad et al., 2005)

Two non-depleting IL-2 receptor antibodies, daclizumab and basiliximab, are being used in liver transplantation for induction immunosuppression in patients with renal failure to allow a delayed introduction of CNI (Verna et al., 2011).

Alemtuzumab has been used in tolerance inducing protocols in liver transplantation but is not currently used outside research protocols (Weissenbacher et al., 2010).

\section{Immunosuppression in pancreas transplantation}

Currently about 1,100 patients receive a pancreas transplant in the US per year. The main indication is to restore normoglycemia in patients with type I diabetes on high insulin regimens to improve or at least to arrest the progression of diabetic nephropathy, retinopathy and neuropathy. The advantages of pancreas transplant versus insulin therapy in obtaining normoglycemia have been well documented (Gremizzi et al., 2010). Hypoglycemia unawareness, a complication of insulin therapy, is also an indication for pancreas transplant. Since the year 2000 islet cell transplant has been introduced as an alternative less invasive treatment for diabetes (Shapiro et al., 2000) with reports of variable 
success over the years (review in (de Kort et al., 2011)). The long term function of transplanted islets remains an unresolved issue. Recent studies report that pancreas transplant obtains higher rates of and longer lasting insulin independence compared to islet cell transplant, but with higher risk of surgical complications (Vardanyan et al., 2010, Maffi et al., 2011). The immunological aspects and immunosuppression regimens specific to islet transplant have been extensively reviewed (Azzi et al., 2010) and will not be discussed here. The pancreas is transplanted either simultaneously with the kidney for patients with renal failure due to type 1 diabetes mellitus or as isolated pancreas. In addition, the pancreas is included in the multivisceral graft for selected patients transplanted for intestinal failure (see below). Advances in surgical techniques and immunosuppression management have obtained current pancreas graft survival rates of $86 \%$ at 1 year, between 60 and $80 \%$ at 3 years and $53 \%$ at 10 years, respectively (Gruessner et al., 2010).

Most pancreas transplant recipients receive induction therapy with T-cell-depleting agents thymoglobulin or alemtuzumab and maintenance immunosuppression with a combination of CNI (mostly tacrolimus), mycophenolate mofetil, sirolimus and rapid steroid withdrawal (review in Heilman et al., 2010). The incidence of acute rejection after pancreas transplant is reported between 20 and 35\% at 3 years (Farney et al., 2009). Like in kidney transplant, the combination of sirolimus with full dose CNI may accentuate nephrotoxicity. There have been trials of elimination of CNI to avoid nephrotoxicity with similar patient and graft survival at 6 months compared to tacrolimus based regimens, but with higher rates of acute rejection (Gruessner et al 2005). Over the last years, more and more maintenance protocols have avoided the use of steroids (Knight et al., 2010).

\section{Immunosuppression in intestinal transplantation}

Intestinal transplantation is the newest and most recently developed among abdominal organ transplants. Although it has been attempted experimentally for decades since the pioneering work of Lillehei (Lillehei et al 1959), the first successful intestinal transplant in humans was reported in 1990 (Grant et al., 1990). Over the last decade intestinal transplantation has become clinically established as an effective treatment for patients with intestinal failure and life-threatening complications of parenteral nutrition (Fishbein 2009). In recent years 150-180 intestinal transplants are performed in US per year. (unos) http://optn.transplant.hrsa.gov/latestData/rptData.asp

Rejection has been a formidable obstacle to successful intestinal transplantation. The development of effective immunosuppression together with advanced surgical techniques and improved patient management have significantly contributed to the success of intestinal transplantation. Although initially rejection and mortality rates were high, the outcomes of intestinal transplantation have markedly improved over the last decade and now survival rates are close to other solid organ transplants. However, still transplantation of the intestine remains a greater immunologic challenge compared to other solid organs. The high immunogenicity of the intestinal graft is related to its rich composition in lymphoid tissue ( $80 \%$ of the body immune cells reside in the gut) and also to the presence of a complex innate immune system continuously exposed to intraluminal foreign antigens and microbes. A delicate and fine balance between absorption of nutrients and defense from infection is regulated at the level of the intestinal surface and the interplay between innate and acquired components of the immune response at the level of the intestinal mucosa is being better understood in recent years (see below). 
The introduction of tacrolimus in the early 1990 and induction immunotherapy (Reyes et al 2005) have decreased the rejection rate from historical rates of 80 or more to $20-40 \%$ in most recent series. Episodes of acute rejection are treated with intravenous pulse steroids and/or thymoglobulin, depending on severity. The severity of rejection episodes has been better controlled with the introduction of sirolimus in addition to tacrolimus-based maintenance immunosuppression (Fishbein et al., 2002, Gupta et al., 2005). Infliximab, an anti-tumor necrosis factor alpha antibody used for Crohn's disease, has been successful in isolated cases as salvage therapy in patients with thymoglobulin resistant rejection (De Greef et al., 2011). Immunosuppression protocols continue to evolve (Abu-Elmagd et al., 2009, Pirenne et al., 2009) and different drug combinations are used with the cornerstone for maintenance immunosuppression being tacrolimus.

New insight in intestine transplant function and on new strategies to control allograft rejection comes from studies on gut microflora and innate immunity. The normal intestinal flora is dominated by anaerobic species Bacteroides and Clostridia. Post-transplant the composition of the gut microflora changes and the microbial community is dominated by Lactobacilli and Enterobacteria, which are facultative anaerobes (Hartman et al., 2009). This represents an inversion of the normal flora. After surgical closure of the ileostomy, which is usually undertaken three months post-transplant, the microbial community reverts to the normal flora. Therefore, the transplanted intestine can function with either of two alternate microbial populations. As in patients with inflammatory bowel disease, the functional impact of alterations in the gut microflora is only recently being recognized and may have implications for the management of intestinal transplant rejection.

The nucleotide-binding oligomerization domain 2 (NOD2) is an intracellular sensor for pathogen/microbe associated molecular patterns that recognizes a component of the bacterial cell wall. NOD2 protein is a critical regulator of bacterial immunity in the intestine and is required for the expression of intestinal anti-microbial peptides. Mutations of NOD2 are highly correlated with Crohn's disease. We found that $35 \%$ of intestinal transplant recipients have NOD2 mutations associated with Crohn's disease and that the risk severe rejection and of graft failure were significantly greater in the NOD2 mutant recipients compared with the NOD2 wild-type recipients (Fishbein et al 2008). The presence of a NOD2 polymorphism in the recipient may influence the viability of the allograft by interrupting NOD2- dependent circuits required to maintain intestinal homeostasis with respect to commensal flora: a recipient lacking a functional intestinal microbial-sensing system may be more exposed to allograft damage secondary to rejection than a recipient with an intact system.

\section{Future perspectives}

Renal function impairment, opportunistic infections (Cytomegalovirus, Epstein-Barr related post-transplant lymphoproliferative disease and others) and metabolic disorders (diabetes and others) are frequent complications of prolonged immunosuppression and remain a major challenge to improve the long term outcomes of transplant recipients. Future strategies to limit the impact of these complications include the development of new nonnephrotoxic agents, the individualization of organ-specific immunosuppression regimens tailored to patient needs and the design of protocols of minimization of immunosuppression and tolerance induction. Studies on gene expression profiling and other methods derived from the -omics approach will further contribute to characterize the rejection process and to monitor the immune response. 
The role of B cells and antibodies is increasingly being investigated and recognized as a target for treatment. The presence and persistence of donor-specific antibodies in the long term follow-up of kidney transplant recipients led to the recognition that chronic antibody mediated injury may be responsible for late graft loss. (Colvin 2010). This has prompted interest in new B-cell based therapeutic strategies and trials are under way involving agents to control humoral immunity.

The contribution of memory T cells (Lo et al., 2011) and of systemic complement activation (Damman et al., 2011) to the rejection process will also be better characterized by ongoing trials.

\section{References}

Abu-Elmagd KM, Costa G, Bond GJ, Wu T, Murase N, Zeevi A, et al. (2009). Evolution of the immunosuppressive strategies for the intestinal and multivisceral recipients with special reference to allograft immunity and achievement of partial tolerance. Transplant International 22 :96-109.

Adcock IM, Ito K. (2000).Molecular mechanisms of corticosteroid actions. Monaldi Arch Chest Dis 55(3):256-66.

Aoyagi T, Yamashita K, Suzuki T, Uno M, Goto R, Taniguchi M, et al. (2009). A human antiCD40 monoclonal antibody, 4D11, for kidney transplantation in cynomolgus monkeys: induction and maintenance therapy. Am J Transplant. 9(8):1732-41.

Aparna P, Augustine JJ, Hricik DE. (2009).Induction Antibody Therapy in Kidney Transplantation. Am J Kidney Dis 54:935-944.

Asrani SK, Leise MD, West CP, Murad MH, Pedersen RA, Erwin PJ, Tian J, Wiesner RH, Kim WR (2010). Use of sirolimus in liver transplant recipients with renal insufficiency: a systematic review and meta-analysis. Hepatology. 52(4):1360-70.

Asthana S, Toso C, Meeberg G (2011). The impact of sirolimus on hepatitis C recurrence after liver transplantation. Can J Gastroenterol, 25(1):28-34.

Azzi J, Geara AS, El-Sayegh S, Abdi R. (2010).Immunological aspects of pancreatic islet cell transplantation. Expert Rev Clin Immunol. 6(1):111-24.

Berenguer M, Palau A, Aguilera V, Rayón JM, Juan FS, Prieto M. (2008).Clinical benefits of antiviral therapy in patients with recurrent hepatitis $C$ following liver transplantation. Am J Transplant. 8(3):679-87.

Berenguer M, Aguilera V, San Juan F, Benlloch S, Rubin A, López-Andujar R, Moya A, Pareja E, Montalva E, Yago M, de Juan M, Mir J, Prieto M. (2010). Effect of calcineurin inhibitors in the outcome of liver transplantation in hepatitis $\mathrm{C}$ viruspositive recipients. Transplantation. 90(11):1204-9.

Berenguer M. (2011).Hot topic debate on HCV: The type of immunosuppression does not matter. Liver Transpl. Jun 1. doi: 10.1002/1t.22347. [Epub ahead of print]

Borie DC, Changelian PS, Larson MJ et al.(2005). Immunosuppression by the JAK3 inhibitor CP-690,550 delays rejection and significantly prolongs kidney allograft survival in nonhuman primates. Transplantation 79: 791-801

Busque S, Leventhal J, Brennan DC, Steinberg S, Klintmalm G, Shah T, Mulgaonkar S, Bromberg JS, Vincenti F, Hariharan S, Slakey D, Peddi VR, Fisher RA, Lawendy N, Wang C, Chan G.(2009). Calcineurin-inhibitor-free immunosuppression based on the JAK inhibitor CP-690,550: a pilot study in de novo kidney allograft recipients. Am J Transplant. 9(8):1936-45 
Busuttil RW, Lake JR.(2004). Role of tacrolimus in the evolution of liver transplantation. Transplantation. 77(9 Suppl):S44-51.

Calne RY (1961) Inhibition of the rejection of renal homografts in dogs by purine analogues. Transpl Bull 28(2):445-461

Campsen J, Zimmerman MA, Mandell S, Kaplan M, Kam I. (2011). A Decade of Experience Using mTor Inhibitors in Liver Transplantation. J Transplant. 2011;2011:913094. Epub 2011 Mar 15.

Chinnakotla S, Davis GL, Vasani S.(2009). Impact of sirolimus on the recurrence of hepatocellular carcinoma after liver transplantation. Liver Transpl, 15(12): 1834-42.

Ciancio G, Gaynor JJ, Zarak A, Sageshima J, Guerra G, Roth D, Brown R, Kupin W, Chen L, Tueros L, Hanson L, Ruiz P, Burke GW 3rd.(2011) Randomized trial of mycophenolate mofetil versus enteric-coated mycophenolate sodium in primary renal transplantation with tacrolimus and steroid avoidance: four-year analysis. Transplantation. 91(11):1198-1205.

Colvin RB, Hirohashi T, Farris AB, Minnei F, Collins AB, Smith RN. (2010). Emerging role of B cells in chronic allograft dysfunction. Kidney Int Suppl. 119:S13-7.

Colvin RB. (2010). Dimensions of antibody-mediated rejection. Am J Transplant. 10(7):1509-10.

Cross SA, Perry CM. (2007).Tacrolimus once-daily formulation in the prophylaxis of transplant rejection in renal or liver allograft recipients. Drugs. 67(13):1931-43.

Damman J, Seelen MA, Moers C, Daha MR, Rahmel A, Leuvenink HG, Paul A, Pirenne J, Ploeg RJ. (2011) Systemic Complement Activation in Deceased Donors Is Associated With Acute Rejection After Renal Transplantation in the Recipient. Transplantation. 92(2):163-169.

Dedrick RL, Walickeb P, Garovoya M. (2002). Anti-adhesion antibodies. Efalizumab, a humanized anti-CD11a monoclonal antibody. Transplant Immunology 9: 181-186.

De Greef E, Avitzur Y, Grant D, De-Angelis M, Ng V, Jones N, Ngan B, Shapiro R, Steinberg R, Gana JC. (2011). The Successful Use of Infliximab as Salvage Therapy in Pediatric Intestinal Transplant Patients with Steroid and Thymoglobulin Resistant Late Acute Rejection. J Pediatr Gastroenterol Nutr. [Epub ahead of print]

de Kort H, de Koning EJ, Rabelink TJ, Bruijn JA, Bajema IM (2011). Islet transplantation in type 1 diabetes. BMJ.;342:d217. doi: 10.1136/bmj.d217.

Eghtesad B, Fung JJ, Demetris AJ, Murase N, Ness R, Bass DC, Gray EA, Shakil O, Flynn B, Marcos A, Starzl TE (2005). Immunosuppression for liver transplantation in HCVinfected patients: mechanism-based principles. Liver Transpl. 11(11):1343-52.

Ellis CN, Krueger GG; Alefacept Clinical Study Group.(2001).Treatment of chronic plaque psoriasis by selective targeting of memory effector T lymphocytes. $N$ Engl J Med. 345(4):248-55

Ekberg H, Tedesco-Silva H, Demirbas A, Vítko S, Nashan B, Gürkan A, Margreiter R, Hugo C, Grinyó JM, Frei U, Vanrenterghem Y, Daloze P, Halloran PF; ELITE-Symphony Study. (2007) Reduced exposure to calcineurin inhibitors in renal transplantation. $N$ Engl J Med. 357(25):2562-75

Ekberg H, Grinyó J, Nashan B, Vanrenterghem Y, Vincenti F, Voulgari A, Truman M, Nasmyth-Miller C, Rashford M. (2007) Cyclosporine sparing with mycophenolate mofetil, daclizumab and corticosteroids in renal allograft recipients: the CAESAR Study. Am J Transplant. 7(3):560-70.

Ekberg H, Bernasconi C, Tedesco-Silva H, Vítko S, Hugo C, Demirbas A, Acevedo RR, Grinyó J, Frei U, Vanrenterghem Y, Daloze P, Halloran P. (2009). Calcineurin 
inhibitor minimization in the Symphony study: observational results 3 years after transplantation. Am J Transplant. 9(8):1876-85.

European FK506 Multicentre Liver Study Group.(1994) Randomised trial comparing tacrolimus (FK506) and cyclosporin in prevention of liver allograft rejection. Lancet. 344(8920):423-8

Farney AC, Doares W, Rogers J, Singh R, Hartmann E, Hart L, Ashcraft E, Reeves-Daniels A, Gautreaux M, Iskandar SS, Moore P, Adams PL, and Stratta RJ.(2009) A Randomized Trial of Alemtuzumab Versus Antithymocyte Globulin Induction in Renal and Pancreas Transplantation.Transplantation 88: 810-819.

Fishbein TM, Florman S, Gondolesi G, Schiano T, LeLeiko N, Tschernia A, Kaufman S. (2002). Intestinal transplantation before and after the introduction of sirolimus. Transplantation. 73(10):1538-42

Fishbein T, Novitskiy G, Mishra L, Matsumoto C, Kaufman S, Goyal S, Shetty K, Johnson L, Lu A, Wang A, Hu F, Kallakury B, Lough D, Zasloff M (2008). NOD2-expressing bone marrow-derived cells appear to regulate epithelial innate immunity of the transplanted human small intestine. Gut. 57(3):323-30.

Fishbein TM.(2009) Intestinal transplantation. N Engl J Med. 361(10):998-1008.

Flanagan ME, Blumenkopf TA,Brissette WH,Brown MF, Casavant JM, Shang-Poa C, Doty JL,Elliott EA, Fisher MB, Hines M, Kent C,Kudlacz EM, Lillie BM, Magnuson KS, McCurdy SP,Munchhof MJ,Perry BD, Sawyer PS, Strelevitz TJ, Subramanyam C,Sun J,Whipple DA, Changelian PS (2010). Discovery of CP-690,550: A Potent and Selective Janus Kinase (JAK) Inhibitor for the Treatment of Autoimmune Diseases and Organ Transplant Rejection J. Med. Chem. 53: 8468-8484.

Flechner SM, Kobashigawa J, Klintmalm G.(2008) Calcineurin inhibitor-sparing regimens in solid organ transplantation: focus on improving renal function and nephrotoxicity. Clin Transplant. 22(1):1-15.

Gabardi S, Baroletti SA. (2010) Everolimus: a proliferation signal inhibitor with clinical applications in organ transplantation, oncology, and cardiology. Pharmacotherapy. 30(10):1044-56.

Gaber AO, Busque S, Mulgaonkar S, Gaston R, Jevnikar A,Meier-Kriesche H-U. (2008) ISA247: A phase IIB multicenter, open label,concentration-controlled trial in de novo renal transplantation. Am J Transplant 8(Suppl 2): 336.

Gaston RS, Kaplan B, Shah T, Cibrik D, Shaw LM, Angelis M, Mulgaonkar S, Meier-Kriesche HU, Patel D, Bloom RD. (2009) Fixed- or controlled-dose mycophenolate mofetil with standard- or reduced-dose calcineurin inhibitors: the Opticept trial. Am J Transplant.9(7):1607-19.

Geissler EK, Schlitt HJ.(2009) Immunosuppression for liver transplantation. Gut 58: 452-463

Geissler EK, Schlitt HJ.(2010) The potential benefits of rapamycin on renal function, tolerance, fibrosis, and malignancy following transplantation. Kidney Int. 78(11):1075-9.

Grant D, Wall W, Mimeault R, Zhong R, Ghent C, Garcia B, (1990) Successful small-bowel/liver transplantation. Lancet 335(8683):181-4.

Gremizzi C, Vergani A, Paloschi V, Secchi A.(2010) Impact of pancreas transplantation on type 1 diabetes-related complications. Curr Opin Organ Transplant. 15(1):119-23. 
Gruessner RW, Kandaswamy R, Humar A, Gruessner AC, Sutherland DE.(2005) Calcineurin inhibitor- and steroid-free immunosuppression in pancreas-kidney and solitary pancreas transplantation. Transplantation 79:1184-1189.

Gruessner AC, Sutherland DE, Gruessner RW (2010) Pancreas transplantation in the United States: a review. Curr Opin Organ Transplant. 15(1):93-101.

Gupta P, Kaufman S, Fishbein TM.(2005) Sirolimus for solid organ transplantation in children. Pediatr Transplant. 9(3):269-76

Harper SJ, Gelson W, Harper IG, Alexander GJ, Gibbs P.(2011) Switching to sirolimus-based immune suppression after liver transplantation is safe and effective: a single-center experience. Transplantation. 91(1):128-32.

Hartman A, Denver ML, Barupal DK, Fiehn O, Fishbein T, Zasloff M and Eisen JA (2009) Human gut microbiome adopts an alternative state following small bowel transplantation PNAS 106(40):17187-17192

Heilman RL, Mazur MJ, Reddy KS. (2010) Immunosuppression in Simultaneous PancreasKidney Transplantation. Progress to Date . Drugs 70 (7): 793-804

(http:/ / optn.transplant.hrsa.gov/ar2009/Chapter_III_AR_CD.htm?cp=4\#1)

Hutchinson M (2010) Natalizumab therapy of multiple sclerosis. J Interferon Cytokine Res. 30(10):787-9.

Kahan BD.(2000) Efficacy of sirolimus compared with azathioprine for reduction of acute renal allograft rejection: a randomized multicentre study. The Rapamune US Study Group. Lancet 356(15):194.

Kaposztas Z, Podder H, Mauiyyedi S, Illoh O, Kerman R, Reyes M, Pollard V, Kahan BD.(2009) Impact of rituximab therapy for treatment of acute humoral rejection. Clin Transplant. 23(1):63-73.

Kirk AD, Turgeon NA, Iwakoshi NN (2010). B cells and transplantation tolerance. Nat Rev Nephrol. 6(10):584-93.

Klipa D, Mahmud N, Ahsan N.(2010) Antibody immunosuppressive therapy in solid organ transplant: Part II. MAbs. 2(6):607-12.

Knechtle SJ. (2010) Immunoregulation and tolerance. Transplant Proc. 42(9 Suppl):S13-5.

Knight RJ, Podder H, Kerman RH, Lawless A, Katz SM,Van Buren CT, Gaber AO, Kahan BD.(2010) Comparing an early corticosteroid/late calcineurin-free immunosuppression protocol to a sirolimus-, cyclosporine A-, and prednisone based regimen for pancreas-kidney transplantation. Transplantation 89:727-732.

Kovarik JM, Steiger JU, Grinyo JM, Rostaing L, Arns W, Dantal J, Proot P, Budde K, Sotrastaurin Renal Transplant Study Group (2011). Pharmacokinetics of sotrastaurin combined with tacrolimus or mycophenolic acid in de novo kidney transplant recipients. Transplantation. 91(3):317-22.

Krämer BK, Charpentier B, Bäckman L, Silva HT Jr, Mondragon-Ramirez G, CassutoViguier E, Mourad G, Sola R, Rigotti P, Mirete JO; Tacrolimus Prolonged Release Renal Study Group.(2010) Tacrolimus once daily (ADVAGRAF) versus twice daily (PROGRAF) in de novo renal transplantation: a randomized phase III study. Am J Transplant. 10(12):2632-43.

Kuschei WM, Leitner J, Majdic O, Pickl WF, Zlabinger GJ, Grabmeier-Pfistershammer K, Steinberger P.(2011) Costimulatory signals potently modulate the T cell inhibitory capacity of the therapeutic CD11a antibody Efalizumab. Clin Immunol. 139(2):199-207.

Larson TS, Dean PG, Stegall MD, Griffin MD, Textor SC, Schwab TR, Gloor TM, Cosio FG, Lund WJ, Kremers WK, Nyberg SL, Ishitani MB, Prieto M, Velosa JA 
(2006).Complete Avoidance of Calcineurin Inhibitors in Renal Transplantation: A Randomized Trial Comparing Sirolimus and Tacrolimus. Am J Transpl 6:514-522

Lillehei RC, Goot B, Miller FA.(1959) The physiological response of the small bowel of the dog to ischemia including prolonged in vitro preservation of the bowel with successful replacement and survival. Ann Surg 150(4): 543-560

Llovet JM, Ricci S, Mazzaferro V(2008). Sorafenib in advanced hepatocellular carcinoma. $N$ Engl J Med 359(8):378-390.

Lo DJ, Weaver TA, Stempora L, Mehta AK, Ford ML, Larsen CP, Kirk AD (2011). Selective targeting of human alloresponsive CD8+ effector memory T cells based on CD2 expression. Am J Transplant. 11(1):22-33.

Maffi P, Scavini M, Socci C, Piemonti L, Caldara R, Gremizzi C, Melzi R, Nano R, Orsenigo E, Venturini M, Staudacher C, Del Maschio A, Secchi A. (2011). Risks and benefits of transplantation in the cure of type 1 diabetes: whole pancreas versus islet transplantation. A single center study. Rev Diabet Stud. 8(1):44-50.

Melancon JK, Cummings LS, Graham J, Rosen-Bronson S, Light J, Desai CS, Girlanda R, Ghasemian S, Africa J, Johnson LB.(2011). Paired kidney donor exchanges and antibody reduction therapy: novel methods to ameliorate disparate access to living donor kidney transplantation in ethnic minorities. J Am Coll Surg. 212(4):740-5.

Mele TS, Halloran PF.(2000) The use of mycophenolate mofetil in transplant recipients. Immunopharmacology 47:215-245.

Melero J, Berenguer M. (2009).Antiviral therapy in patients with HCV-cirrhosis. Ann Hepatol. $8(4): 292-7$.

Merion RM, White DJ, Thiru S, Evans DB, Calne RY.(1984). Cyclosporine: five years' experience in cadaveric renal transplantation. N Engl J Med. 310(3):148-54

Montgomery RA, Gentry SE,Marks WH. (2006). Domino paired kidney donation: a strategy to make best use of live non-directed donation. Lancet 368:419-421.

Montgomery RA. (2010) Renal transplantation across HLA and ABO antibody barriers: integrating paired donation into desensitization protocols. Am J Transplant 10:449457.

Nazia S, Guindi M, Renner EL, Berenguer M. (2011). Immune-mediated complications of the graft in interferon-treated hepatitis $\mathrm{C}$ positive liver transplant recipients. J of Hepatol 55: 207-217

Niederhaus SV, Muth B, Lorentzen DF, Wai P, Pirsch JD, Samaniego-Picota M, Leverson GE, D'alessandro AM, Sollinger HW, Djamali A. (2011) Luminex-based desensitization protocols: the university of wisconsin initial experience. Transplantation. 92(1):12-7.

Ojo AO, Held PJ, Port FK, Wolfe RA, Leichtman AB, Young EW, Arndorfer J, Christensen L, Merion RM.(2003) Chronic renal failure after transplantation of a nonrenal organ. $N$ Engl J Med. 349(10):931-40

Perry DK, Burns JM, Pollinger HS, Amiot BP, Gloor JM, Gores GJ, Stegall MD. (2009). Proteasome Inhibition Causes Apoptosis of Normal Human Plasma Cells Preventing Alloantibody Production. Am J Transpl 9(1) 201-209.

Pillai AA, Levitsky J.(2009) Overview of immunosuppression in liver transplantation. World J Gastroenterol. 15(34):4225-33.

Pirenne J, Kawai M.(2009). Intestinal transplantation: evolution in immunosuppression protocols. Current Opinion in Organ Transplantation 14:250-255

Raichlin E, Khalpey Z, Kremers W, Frantz RP, Rodeheffer RJ, Clavell AL, Edwards BS, Kushwaha SS. (2007). Replacement of calcineurin-inhibitors with sirolimus as 
primary immunosuppression in stable cardiac transplant recipients.Transplantation. 84(4):467-74.

Reyes J, Mazariegos GV, Abu-Elmagd K, Macedo C, Bond GJ, Murase N, Peters J, Sindhi R, Starzl TE. (2005). Intestinal transplantation under tacrolimus monotherapy after perioperative lymphoid depletion with rabbit anti-thymocyte globulin (thymoglobulin). Am J Transplant. 5(6):1430-6.

Rosen HR, Shackleton CR, Higa L, Gralnek IM, Farmer DA, McDiarmid SV, Holt C, Lewin KJ, Busuttil RW, Martin P.(1997) Use of OKT3 is associated with early and severe recurrence of hepatitis C after liver transplantation. Am J Gastroenterol. 92(9):1453-7

Schena FP, Pascoe MD, Alberu J, del Carmen Rial M, Oberbauer R, Brennan DC, Campistol JM, Racusen L, Polinsky MS, Goldberg-Alberts R.(2009). Conversion from calcineurin inhibitors to sirolimus maintenance therapy in renal allograft recipients: 24-month efficacy and safety results from the CONVERT trial. Transplantation. 87(2):233-42.

Shapiro AMJ, Lakey JRT, Ryan EA, Korbutt GS, Toth E, Warnock GL.(2000) Islet transplantation in seven patients with type 1 diabetes mellitus using a glucocorticoid-free immunosuppressive regimen. N Engl J Med 343:230-8.

Starzl TE, Marchioro TL, Hutchinson DE, Porter KA, Cerilli GJ, Brettschneider L.(1967) The clinical use of antilymphocyte globulin in renal homotransplantation. Transplantation. 5(4):Suppl:1100-5.

Starzl TE.(2000) History of clinical transplantation. World J Surg. 24(7):759-82.

Starzl TE, Iwatsuki S, Shaw BW Jr, Gordon RD, Esquivel CO (1985) Immunosuppression and other nonsurgical factors in the improved results of liver transplantation. Semin Liver Dis. 5(4):334-43.

Starzl TE, Todo S, Fung J, Demetris AJ, Venkataramman R, Jain A (1989). FK 506 for liver, kidney, and pancreas transplantation. Lancet. 8670 (2):1000-4.

Stewart SF, Hudson M, Talbot D, Manas D, Day CP.(2001) Mycophenolate mofetil monotherapy in liver transplantation. Lancet 357: 609-610

The U.S. Multicenter FK506 Liver Study Group.(1994) A comparison of tacrolimus (FK 506) and cyclosporine for immunosuppression in liver transplantation. $N$ Engl J Med. 331(17):1110-5.

Toso C, Merani S, Bigam DL.(2010). Sirolimus-based immunosuppression is associated with increased survival after liver transplantation for hepatocellular carcinoma. Hepatology, 51(4): 1237-43.

Treiber G.(2009) mTOR inhibitors for hepatocellular cancer: a forward-moving target. Expert Rev Anticancer Ther. 9(2):247-61.

Trunečka P, Boillot O, Seehofer D, Pinna AD, Fischer L, Ericzon BG, Troisi RI, Baccarani U, Ortiz de Urbina J, Wall W.(2010). Once-daily prolonged-release tacrolimus (ADVAGRAF) versus twice-daily tacrolimus (PROGRAF) in liver transplantation. Tacrolimus Prolonged Release Liver Study Group. Am J Transplant. 10(10):2313-23.

Vardanyan M, Parkin E, Gruessner C, Rodriguez Rilo HL. (2010) Pancreas vs. islet transplantation: a call on the future. Curr Opin Organ Transplant. 15(1):124-30.

Verna EC, Farrand ED, Elnaggar AS, Pichardo EM, Balducci A, Emond JC, Guarrera JV,Brown RS (2011). Basiliximab Induction and Delayed Calcineurin Inhibitor Initiation in Liver Transplant Recipients With Renal Insufficiency. Transplantation 91: 1254-1260. 
Villanueva A, Llovet JM.(2011) Targeted therapies for hepatocellular carcinoma. Gastroenterology. 140(5):1410-26.

Vincenti F, Ramos E, Brattstrom C, Cho S, Ekberg H, Grinyo J, Johnson R, Kuypers D, Stuart F, Khanna A, Navarro M, Nashan B.(2001) Multicenter trial exploring calcineurin inhibitors avoidance in renal transplantation.Transplantation. 71(9):1282-7.

Vincenti F, Larsen C, Durrbach A, Wekerle T, Nashan B, Blancho G, Lang P, Grinyo J, Halloran PF, Solez K, Hagerty D, Levy E, Zhou W, Natarajan K, Charpentier B for the Belatacept Study Group (2005). Costimulation Blockade with Belatacept in Renal Transplantation. N Engl J Med 353:770-781

Vincenti F, Mendez R, Pescovitz M, Rajagopalan PR, Wilkinson AH, Butt K, Laskow D, Slakey DP, Lorber MI, Garg JP, Garovoy M (2007) A phase I/II randomized openlabel multicenter trial of efalizumab, a humanized anti-CD11a, anti-LFA-1 in renal transplantation. Am J Transplant. 7(7):1770-7.

Vincenti F, Blancho G, Durrbach A, Friend P, Grinyo J, Halloran PF, Klempnauer J, Lang P, Larsen CP, Mühlbacher F, Nashan B, Soulillou JP, Vanrenterghem Y, Wekerle T, Agarwal M, Gujrathi S, Shen J, Shi R, Townsend R, Charpentier B. (2010). Five-year safety and efficacy of belatacept in renal transplantation. J Am Soc Nephrol. 21(9):1587-96.

Wagner D, Kniepeiss D, Schaffellner S. (2010). Sirolimus has a potential to influent viral recurrence in $\mathrm{HCV}$ positive liver transplant candidates. Int Immunopharmacol, 10(8):990-3.

Walsh RC, Everly JJ, Brailey P, Rike AH, Arend LJ, Mogilishetty G, Govil A, RoyChaudhury P, Alloway RR, Woodle ES. (2010). Proteasome inhibitor-based primary therapy for antibody-mediated renal allograft rejection. Transplantation. 89(3):27784.

Walsh RC, Brailey P, Girnita A, Alloway RR, Shields AR, Wall GE, Sadaka BH, Cardi M, Tevar A, Govil A, Mogilishetty G, Roy-Chaudhury P, Woodle ES.(2011). Early and late acute antibody-mediated rejection differ immunologically and in response to proteasome inhibition. Transplantation. 91(11):1218-26

Weaver TA, Charafeddine AH, Agarwal A,1 Leopardi F, Kampen R, Starost MF,Larsen CP, Kirk AD.(2008) Targeting of Costimulation Blockade Resistant T Effector Memory (TEM) Cells in Non-Human Primate Renal Transplantation withLFA-3-Ig (Alefacept) Prolongs Allograft Survival. Am J Transpl 8(suppl2):204

Wéclawiak H, Kamar N, Ould-Mohamed A, Cardeau-Desangles I, Rostaing L.(2010) Biological agents in kidney transplantation: belatacept is entering the field. Expert Opin Biol Ther. 10(10):1501-8.

Weissenbacher A, Boesmueller C, Brandacher G, Oellinger R, Pratschke J, Schneeberger S.(2010) Alemtuzumab in solid organ transplantation and in composite tissue allotransplantation. Immunotherapy. 2(6):783-90.

Wiesner, R, for the Rapamune Liver Transplant Study Group (2002) The safety and efficacy of sirolimus and low-dose tacrolimus vs. tacrolimus in de novo orthotopic liver transplant recipients: results from a pilot study. Hepatology, 36: 208A.

Wolfe RA, Roys EC, Merion RM. (2010) Trends in organ donation and transplantation in the United States, 1999-2008. Am J Transplant. 10(4 Pt 2):961-72. 


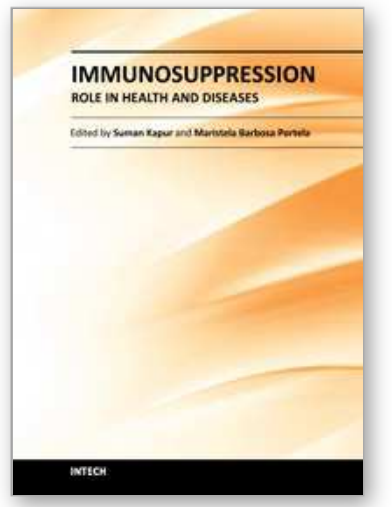

\author{
Immunosuppression - Role in Health and Diseases \\ Edited by Dr. Suman Kapur
}

ISBN 978-953-51-0152-9

Hard cover, 470 pages

Publisher InTech

Published online 24, February, 2012

Published in print edition February, 2012

A need for a book on immunology which primarily focuses on the needs of medical and clinical research students was recognized. This book, "Immunosuppression - Role in Health and Diseases" is relatively short and contains topics relevant to the understanding of human immune system and its role in health and diseases. Immunosuppression involves an act that reduces the activation or efficacy of the immune system. Therapeutic immunosuppression has applications in clinical medicine, ranging from prevention and treatment of organ/bone marrow transplant rejection, management of autoimmune and inflammatory disorders. It brings important developments both in the field of molecular mechanisms involved and active therapeutic approaches employed for immunosuppression in various human disease conditions. There was a need to bring this information together in a single volume, as much of the recent developments are dispersed throughout biomedical literature, largely in specialized journals. This book will serve well the practicing physicians, surgeons and biomedical scientists as it provides an insight into various approaches to immunosuppression and reviews current developments in each area.

\title{
How to reference
}

In order to correctly reference this scholarly work, feel free to copy and paste the following:

Raffaele Girlanda, Cal S. Matsumoto, Keith J. Melancon and Thomas M. Fishbein (2012). Current Immunosuppression in Abdominal Organ Transplantation, Immunosuppression - Role in Health and Diseases, Dr. Suman Kapur (Ed.), ISBN: 978-953-51-0152-9, InTech, Available from:

http://www.intechopen.com/books/immunosuppression-role-in-health-and-diseases/currentimmunosuppression-in-abdominal-organ-transplantation

\section{INTECH}

open science | open minds

\section{InTech Europe}

University Campus STeP Ri

Slavka Krautzeka 83/A

51000 Rijeka, Croatia

Phone: +385 (51) 770447

Fax: +385 (51) 686166

www.intechopen.com
InTech China

Unit 405, Office Block, Hotel Equatorial Shanghai

No.65, Yan An Road (West), Shanghai, 200040, China 中国上海市延安西路65号上海国际贵都大饭店办公楼 405 单元

Phone: +86-21-62489820

Fax: $+86-21-62489821$ 
(C) 2012 The Author(s). Licensee IntechOpen. This is an open access article distributed under the terms of the Creative Commons Attribution 3.0 License, which permits unrestricted use, distribution, and reproduction in any medium, provided the original work is properly cited. 